\title{
El tópico de Venecia como ciudad del amor en la literatura y la publicidad
}

\author{
Rocío PeÑalta Catalán \\ rociopenalta@filol.ucm.es
}

\begin{abstract}
RESUMEN
«La ciudad del amor» es un epíteto que en muchas ocasiones aparece asociado al nombre de Venecia. El objetivo de este trabajo es analizar el posible origen de este tópico y poner de manifiesto cómo la publicidad turística ha explotado esta idea de la ciudad del amor para vender viajes «románticos» a Venecia. En primer lugar, se investiga de dónde procede este tópico analizando los testimonios de algunos viajeros que visitan Venecia en diferentes momentos, especialmente durante los siglos XVIII y XIX. A continuación, se muestran ejemplos de la publicidad de agencias de viajes, compañías aéreas o empresas organizadoras de bodas que continúan explotando la idea de la ciudad del amor para vender sus productos.
\end{abstract}

Palabras clave: Venecia, ciudad del amor, viajes, publicidad turística, tópicos urbanos.

The Topic of Venice as a City of Love in Literature and Advertising

\begin{abstract}
City of love is an epithet that appears often associated with the name of Venice. The objective of this paper is to analyse the possible origin of this topic and to state how tourism advertising has exploited this idea of the city of love to sell «romantic» travels to Venice. Firstly, it is neccesary to investigate where this topic comes from analysing the testimonies of some travellers who visit Venice at different times, especially during the eighteenth and nineteenth centuries. The following are examples of advertising for travel agencies, airlines or companies organizing weddings that continue to exploit the idea of the city of love in order to sell their products.
\end{abstract}

Keywords: Venice, city of love, travels, tourism advertising, urban topics.

«La ciudad del amor» es un epíteto que en muchas ocasiones aparece asociado al nombre de Venecia. El objetivo de este trabajo es analizar el posible origen de este tópico y poner de manifiesto cómo la publicidad turística ha explotado esta idea de la ciudad del amor para vender viajes «románticos» a Venecia. En primer lugar, se 
investiga de dónde procede este tópico analizando los testimonios de algunos viajeros que visitan Venecia en diferentes momentos, especialmente durante los siglos XVIII y XIX. A continuación, se muestran ejemplos de la publicidad de agencias de viajes, compañías aéreas o empresas organizadoras de bodas que continúan explotando la idea de la ciudad del amor para vender sus productos ${ }^{1}$.

Venecia es considerada una de las ciudades más románticas del mundo y -al igual que París, Praga y Verona- reivindica el título de «ciudad del amor». No está muy claro el origen de este tópico. Tal vez se deba a las conquistas que Giacomo Casanova realizó en esta ciudad en el siglo XVIII o a la gran cantidad de cortesanas que residían en la ciudad de los canales, cuya belleza y celebridad eran motivo de orgullo para los venecianos (Diehl 1961: 230). A ellas se refiere el presidente del Parlamento de Borgoña Charles De Brosses, que visita la ciudad en 1739, en los siguientes términos:

Constituyen un cuerpo verdaderamente respetable por sus buenos procedimientos. No se crea que, como se dice, su número sea tan grande que pase de la marca; eso no sucede más que en la época de Carnaval; fuera de este, su número no pasa del doble de las que hay en París, diferenciándose de las de París en que todas son de una suavidad de carácter y de una finura encantadoras. (De Brosses apud Diehl 1961: 229-230)

La fama de las cortesanas traspasaba las fronteras de la Serenísima República ya en el siglo XVII. Durante la época del Grand Tour, en el momento de máximo auge de este viaje iniciático y formativo que llevaba a los jóvenes, especialmente británicos, a realizar un recorrido por Europa como etapa última de su formación, ya se debatían los peligros de visitar Italia y, concretamente, Venecia. El Grand Tour debía contribuir a la educación del joven en muy diferentes aspectos: debía refinar su sensibilidad estética y moral, enseñarle a controlar su ardor juvenil para sustituirlo por un virtuoso dominio de sus impulsos; por otra parte, con el viaje se combatía la ignorancia derivada de una vida provinciana y sedentaria, y se aprendían otros idiomas distintos de la lengua materna (De Seta 1996: 9-10). Sin embargo, los resultados del viaje no siempre eran los deseados.

El Grand Tour comportaba algunos riesgos, y no nos referimos en este caso a los bandoleros que asaltaban a los forasteros en caminos poco frecuentados, ni a los posaderos que trataban de estafar o robar a sus clientes. El viaje por Italia y, especialmente a Venecia, podía ser contraproducente para la educación del joven aristócrata. Las saludables costumbres de su país podían ser corrompidas por los hábitos extranjeros, y la libertad podía transformarse en libertinaje.

En la ciudad de los canales, los jóvenes corrían el riesgo de perder el tiempo en cafés con malas compañías y de gastar su dinero en trajes, joyas y otros aderezos -que tanto gustaban en Venecia y que tan fácilmente podían encontrarse en sus mer-

${ }^{1}$ La literatura de ficción que, en ocasiones, ha contribuido a perpetuar este tópico, también ha dado lugar a la desmitificación de la ciudad de los enamorados, como es el caso de La isla inaudita de Eduardo Mendoza (vid. Peñalta Catalán 2012). 
cados. Por otra parte, Italia se asociaba con las prácticas homosexuales y se temía que el viajero regresase a su país de origen convertido en un afeminado ${ }^{2}$. Eso por no hablar de las ya mencionadas cortesanas. De esta manera, se temía que el joven, después de su estancia en Venecia, volviese convertido en un «dandi sifilítico» (Redford 1996: 18).

Venecia es la ciudad de los placeres y, como señala el propio Giacomo Casanova (1982: 663), lo único que se necesita para disfrutarlos es juventud, salud, dinero y audacia, características que no faltaban a los jóvenes viajeros. En la Serenísima les esperaban todo tipo de placeres y diversiones, desde suntuosos banquetes regados con abundante vino, hasta el juego y las apuestas en los casinos; pasando, por supuesto, por la agradable compañía femenina.

Son muchos los visitantes que alaban la belleza de las venecianas, su elegancia, la riqueza de sus vestidos. Lo cierto es que en Venecia, tanto los hombres como las mujeres ponían mucho esmero en mostrar un aspecto cuidado y elegante. Los afeites, las pelucas, las pomadas, los polvos, los lunares postizos, los perfumes, los tocados eran elementos imprescindibles en la moda veneciana. Se cuidaba hasta el último detalle y todos querían ir vestidos a la moda, aunque ésta cambiaba constantemente (vid. Vitali 1992). Era tal la ostentación y el derroche en cuestión de vestuario que, en determinado momento de crisis, la República impuso leyes suntuarias para frenar estos excesos. Esto chocaba, evidentemente, con la pretensión de inculcar sobriedad y mesura a los jóvenes, uno de los objetivos del Grand Tour.

Pero no era sólo de la belleza de las mujeres y sus provocativos atuendos los que podían tentar a los jóvenes visitantes. Toda la ciudad de Venecia parecía ser un escenario apropiado para la seducción: los callejones poco transitados ofrecían cobijo a los amantes furtivos; la institución del cicisbeo, un caballero sirviente, amigo y confidente que acompañaba en todo momento a la mujer, incluso si ésta estaba casada, era plenamente aceptada en la sociedad veneciana; las fiestas en los palacios favorecían los encuentros entre hombres y mujeres; la transgresión que suponía el Carnaval -que duraba prácticamente seis meses al año en el siglo XVIII (Barbier 2005: 62) - y el anonimato que conferían la máscara y el disfraz permitían que se cometiesen todo tipo de tropelías, incluso en los conventos y en el interior de las iglesias; $y$, por supuesto, las góndolas eran un elemento imprescindible en la ciudad del amor.

La intimidad de la góndola, que todavía en el siglo XIX tenía felze, la cabina cerrada en la que viajaba el pasajero, es comentada en muchos libros y guías sobre la ciudad. Henry James, que visitó Venecia en varias ocasiones, entre 1869 y 1907, ofrece esta sugerente descripción:

${ }^{2}$ La figura del «macaroni» -término procedente del italiano maccherone, persona necia y ostentosa- está muy relacionada con los temores descritos. En la Inglaterra del siglo XVIII este término se adoptó para designar a aquellos jóvenes obsesionados por la moda y que hablaban y vestían de modo amanerado, mezclando una pose importada de la Europa continental con los hábitos ingleses (Redford 1996: 19). 
La pequeña cabina cerrada de este vehículo perfecto, el movimiento, la oscuridad y el sonido del agua al salpicar, los indistinguibles virajes y giros, todo aquello que no se ve y todo aquello que se siente -cada tenue reconocimiento y oscura atracción es un pálpito de que uno se desliza hacia su destino, aunque en verdad sea una visita simple y social a tomar el té-. En ningún otro lugar algo tan inocente resulta tan misterioso [...]. (James 2008: 148)

Maximilien Misson, autor de una popular guía de Italia dirigida a los viajeros que emprenden el Grand Tour, A new voyage to Italy (1699), no pierde la oportunidad de comentar las intrigas y tejemanejes de los gondoleros, y aconseja a los viajeros que desconfíen de ellos. A pesar de todo, el gondolero se perfila como un individuo discreto, capaz de guardar en secreto todo lo que ocurre a bordo de su embarcación (Misson 1699: 204). Y es que en el interior de la cabina de una góndola puede suceder cualquier cosa, desde un encuentro amoroso hasta una conspiración política. En muchas ocasiones, el propio gondolero ofrece al viajero la compañía de una dama o ejerce como intermediario o mensajero para acordar un encuentro amoroso.

El presidente Charles de Brosses no se priva de ninguno de los placeres que ofrece la ciudad y, en el momento de su partida, lo que más lamenta no es abandonar la ciudad de los canales, sino tener que dejar las «dulces góndolas» y, por supuesto, separarse de sus queridas «Ancilla, Camilla, Faustolla, Zulietta, Angeletta, Caltina, Spina, Agatina, y de otras cien mil cosas terminadas en $a$, cada cual más bonita que la otra».

C'est demain cependant qu'il me faudra quitter mes douces gondoles. J'y suis actuellement en robe de chambre et en pantoufles à vous écrire, au beau milieu de la grande rue, bercé par intérim d'une musique céleste. Qui pis est, il faudra me séparer de mes chères Ancilla, Camilla, Faustolla, Zulietta, Angeletta, Caltina, Spina, Agatina, et de cent mille autres choses en $a$ plus jolies les unes que les autres. (Brosses 1931: 241)

Los encuentros entre hombres y mujeres $-\mathrm{y}$ no nos referimos ahora únicamente a las cortesanas- eran tan fáciles y frecuentes en la ciudad, que muchas mujeres procedentes de otras zonas de Italia se trasladaban a Venecia en busca de esposo ${ }^{3}$. Según explica Giacomo Casanova en sus Memorias, para que una señorita lograra casarse en Venecia era fundamental que cumpliese ciertos requisitos: debía saber música y tocar algún instrumento, bailar o actuar; además, debía tener modales y hablar adecuadamente. Aunque - añade a continuación- en la Venecia del siglo XVIII no todas las señoritas respondían a las características deseadas y era frecuente que las mujeres más vulgares y descaradas apareciesen siempre rodeadas de hombres (Casanova 1982: 745).

Todas las características enumeradas hasta ahora parecen justificar esta visión estereotipada de la Serenísima. Incluso hoy en día, los libros de viajes actuales recogen este tópico e intentan explicarlo. Es el caso de Tiziano Scarpa, que en su guía Venecia es un pez (2000) explica por qué Venecia es el lugar apropiado para conquistar a la persona amada. Según Scarpa, el entorno es un elemento fundamental

${ }^{3}$ Sobre la libertad que tenían las mujeres, incluso las monjas y novicias, para encontrarse con sus enamorados, vid. Ravoux-Rallo (2001: passim). 
para la seducción, y en Venecia, el decorado es inmejorable:

Ci si inamora più facilmente, a Venezia? Il cuore batte più forte? Conviene venirci con la fidanzatta? Si ottengono resultati concreti alleandosi a Venezia per fare fessa una ragazza? Indubbiamente sì. [...] questi vecchi trucchetti -circondarsi di un paesaggio splendido, ammantarsi di una scenografia suggestiva per sedurre- [...]. Voglio far colpo, mi presento davanti a uno sfondo bellissimo, come se fosse il mio corpo a springionare intorno a sé un alone di immagini meravigliose: il paesaggio diventa la mia aureola. [...] è come se il paesaggio si concentrasse in certi punti nodali; lo sfondo si addensa, si cristallizza in una figura che sono io. (Scarpa 2008: 30)

¿Es más fácil enamorarse en Venecia?, se pregunta. ¿Hay que ir a Venecia con el enamorado o la enamorada? Todo parece indicar que sí. Según Scarpa, rodearse de una escenografía sugerente es importante para seducir a otra persona con éxito: «el paisaje se convierte en mi aureola», la belleza del entorno parece contagiarse a las personas que se mueven en él ${ }^{4}$.

En cualquier caso e independientemente del origen del tópico, esta imagen de la ciudad del amor ha sido explotada por las agencias de viajes para vender estancias románticas a las parejas de recién casados, e incluso el propio Ayuntamiento de Venecia, en su página web, consagra un apartado especial a los matrimonios, dirigido a todas aquellas parejas que quieran celebrar su enlace en «la città più romantica del mondo» (Comune di Venezia 2010).

Parece que la idea de casarse en Venecia, ya popular en el siglo XVIII como puede deducirse del testimonio de Casanova, se ha popularizado, y son muchas las parejas que deciden celebrar su matrimonio en la ciudad de los canales. Así, numerosas empresas especializadas en la organización de bodas ofrecen esta misma posibilidad a los enamorados, pues «Venecia es el lugar ideal para celebrar una boda romántica» (Regency) o «Casarse en Venecia: vuestro sueño se hace realidad», como indican los responsables de Serenissima Weddings. Y no sólo para casarse, la ciudad de San Marcos también es el lugar ideal para hacer una declaración de amor:

¿Dónde si no Venecia, el sitio más romántico, para hacer una propuesta de matrimonio? El amor de tu vida se está imaginando unas simples vacaciones en Venecia mientras nosotros organizaremos una propuesta de matrimonio por sorpresa para ti. Imagínate pedirle la mano a tu amor mientras estás en el Puente de los Suspiros. Te aseguramos que se acordará de tu declaración para toda la vida. [...] Para que tu declaración sea aún más inolvidable, un operador de cámara escondido entre la gente rodará la entera escena de los pétalos que caen desde el puente. (Serenissima Weddings)

Son muchos los famosos que, siguiendo estos consejos, han decidido celebrar su enlace en Venecia, como por ejemplo el director de cine Woody Allen, cuya boda

${ }^{4}$ Sin embargo, la Venecia actual presenta ciertos obstáculos al encuentro de los enamorados, pues no existen apenas jardines donde esconderse de las miradas curiosas, ni tampoco coches, que sustituirían a las desaparecidas cabinas cerradas de las góndolas (vid. Doveandamio 2010). 
con Soon-Yi fue celebrada en 1997 en el palazzo Cavalli, sede del ayuntamiento, y oficiada por el alcalde Massimo Cacciari (Berendt 2006: 120); o la actriz mexicana Salma Hayek, que contrajo matrimonio en abril de 2009 con el multimillonario francés François-Henri Pinault, nada menos que en el teatro La Fenice (EFE y AFP 2009). También Javier Bardem, según publicó en su momento la prensa, le propuso matrimonio a Penélope Cruz en la ciudad de los canales, precisamente cuando acudieron como invitados a la boda de Hayek y Pinault (Telecinco 2009). ¿Y qué mejor lugar para celebrar San Valentín o un aniversario que Venecia? Eso mismo parece opinar Norma Duval, que ha celebrado «un año de amor en Venecia» con su pareja (La Voz Libre 2011). El último en sumarse a esta moda ha sido el actor norteamericano George Clooney, que contrajo matrimonio con la abogada libanesa Amal Alamuddin en septiembre de 2014 en la ciudad de los canales. La ceremonia civil, celebrada en Ca' Farsetti -el ayuntamiento veneciano-, fue oficiada por Walter Veltroni, ex alcalde de Roma y amigo de Clooney (Frizell 2014; El Huffington Post 2014).

Así, las agencias de viajes aprovechan este tópico para ofrecer «escapadas románticas» a la Serenísima, y las compañías aéreas diseñan su publicidad y sus promociones en torno a esta manida idea. Por ejemplo, Air France ofrece la posibilidad de participar en el concurso «Palabras de amor que te harán volar» escribiendo un poema de amor original e inédito; los concursantes premiados ganarán viajes para dos personas a París y Venecia, destinos románticos por excelencia. EasyJet, en una de sus últimas campañas, anunciaba sus ofertas en vuelos a Venecia con el siguiente eslogan: «¿Por qué San Valentín tiene que ser el 14 de febrero?», estableciendo una evidente relación entre el día de los enamorados y la ciudad del amor. Son muchos más los ejemplos que pueden encontrarse, pues la publicidad de Venecia basada en este tópico es muy abundante.

En estos tiempos, en que las ciudades se ofertan al turismo como un producto de consumo, cabría preguntarse por qué algunos lugares deciden mostrarse deliberadamente de acuerdo con las imágenes consagradas por la tradición y los tópicos de los libros de viaje (Lucas 2011: 114). Pero el caso es que, viendo la cantidad de turistas que cada año visita Venecia, podemos decir que esta estrategia funciona.

Como conclusión, podemos añadir un último comentario de un célebre viajero: quizá sea la propia ciudad, como escribe Henry James, la que «torna la visita en un romance perpetuo».

Es viviendo en Venecia día tras día como se siente la plenitud de su encanto, como se invita a que su exquisito influjo se hunda en el espíritu. [...] El lugar se personifica, se hace humano, sensible y cobra consciencia del afecto. Uno desea abrazarlo, acariciarlo, poseerlo, y finalmente surge un tenue sentido de posesión que torna la visita en un romance perpetuo. (James 2008: 60-61)

\section{Bibliografía}

BARBIER, Patrick (2005): La Venecia de Vivaldi: Música y fiestas barrocas. Traducción de Jordi Terré. Barcelona: Paidós. 
BERENDT, John (2006): La ciudad de los ángeles caídos. Traducción de Cruz Rodríguez Juiz. Barcelona: Mondadori.

Brosses, Charles de (1931): Lettres familières sur l'Italie, vol. 1. Paris: Librairie de Paris / Firmin-Didot et Cie.

Casanova, Giacomo (1982): Memorias, tomo I. Traducción de Gloria Camarero. Madrid: Aguilar.

Comune di Venezia (2010): «Sposarsi a Venezia» [en línea], en Città di Venezia, última actualización: 18/01/2010. En: http://www.comune.venezia.it/flex/cm/pages/ServeBLOB.php/L/IT/IDPagina/3503 [Consulta: 07/05/2011].

DE SETA, Cesare (1996): L'Italia del Grand Tour: da Montaigne a Goethe. Napoli: Electa Napoli.

DieHL, Carlos (1961): Una república de patricios: Venecia. Madrid: Espasa-Calpe.

Doveandamio (2010): «Venecia, ¿la ciudad de los enamorados?» [en línea], en Doveandamio, 06/09/2010. En: http://doveandamio.blogia.com/2010/090601-venecia-la-ciudadde-los-enamorados-.php [Consulta: 19/02/2013].

EFe y Afp (2009): «Desfile de estrellas en la boda de Salma Hayek en Venecia» [en línea], en Elmundo.es, 26/04/2009. En: http://www.elmundo.es/elmundo/2009/04/25/gentes/1240694472.html [Consulta: 06/05/2011].

El Huffington Post (2014): «Fotos boda George Clooney en Venecia: así han sido los cuatro días de fiesta» [en línea]. El Huffington Post, 29/09/2014. En: http:/www.huffingtonpost.es/2014/09/29/boda-george-clooney_n_5899246.html?utm_hp_ref=mostpopular [Consulta: 02/10/2014].

Frizell, Sam (2014): «George Clooney and Amal Alamuddin Get Married in Venice» [en línea]. Time, 27/09/2014. En: http://time.com/3437763/george-clooney-amal-alamuddin-married/ [Consulta: 02/10/2014].

JAMES, Henry (2008): Horas venecianas. Madrid: Abada.

LA Voz Libre (2011): «Norma Duval y Matthias Kühn celebran un año de amor en Venecia y Barcelona» [en línea], en La voz libre, 10/03/2011. En: http://www.lavozlibre.com/ noticias/ampliar/215568/norma-duval-y-matthias-kuhn-celebran-un-ano-de-amor-envenecia-y-barcelona [Consulta: 21/04/2011].

LuCAS, Patricia (2011): «Estambul otomano de Juan Goytisolo: lo propio y lo ajeno» [en línea]. Ángulo Recto. Revista de estudios sobre la ciudad como espacio plural, vol. 3, núm. 1, pp. 99-116. En: http://www.ucm.es/info/angulo/volumen/Volumen031/varia02.htm [Consulta: 01/05/2011].

Misson, Maximilien (1699): A new voyage to Italy: with curious observations on several other Countries, as, Germany, Switzerland, Savoy, Geneva, Flanders and Holland. Together, with useful Instructions for those who shall Travel thither, 2 vols. London: R. Bentley, M. Wotton, T. Goodwin \& S. Manship.

Peñalta Catalán, Rocío (2012): «La publicidad turística como generadora de tópicos: la desilusión del viajero en La isla inaudita de Eduardo Mendoza», en Diana López Martínez (ed.), Actas del XII Congreso Internacional de Literatura Española Contemporánea. El papel de la literatura, el cine y la prensa (TV/Internet/MAV) en la configuración y promoción de criterios, valores y actitudes sociales, pp. 459-470. Santiago de Compostela: Andavira.

RaVOuX-RaLlo, Elisabeth (2001): Las mujeres en la Venecia del siglo XVIII. Traducción de Teresa Garín. Madrid: Editorial Complutense.

REDFORD, Bruce (1996): Venice \& the Grand Tour. New Haven \& London: Yale University Press. 
REGENCY (s.f.): «Bodas en Venecia» [en línea], en Weddings in Italy. En: http://www.weddingsitaly.com/es/bodas-en-venecia/ [Consulta: 06/05/2011].

SCARPA, Tiziano (2008): Venezia è un pesce: Una guida. Milano: Feltrinelli.

SERENISSIMA WedDings (s.f.): «Casarse en Venecia: vuestro sueño se hace realidad» [en línea], en Serenissima Weddings. En: http://www.serenissima-weddings.com/boda_en_ venecia/index.htm [Consulta: 06/05/2011].

Telecinco (2009): «Suenan campanas de boda para Bardem y Pé» [en línea], en Telecinco.es, 07/05/2009. En: http://telecinco.es/elprogramadeanarosa/detail/detail12995.shtml [Consulta: 06/05/2011].

Vitali, Achille (1992): La moda a Venezia attraverso i secoli. Lessico Ragionato, 2 vols. Venezia: Filippi Editore. 